\title{
LARYNOGOLOGY
}

\section{There is no correlation between signs of reflux laryngitis and reflux oesophagitis in patients with gastro-oesophageal reflux disease symptoms}

\author{
Non c'è nessuna correlazione tra segni di laringite da reflusso ed esofagite \\ da reflusso nei pazienti con sintomi da malattia da reflusso gastroesofageo \\ K. ZELENIIK ${ }^{12}$, I.M. KAJZRLIKOVA ${ }^{3}$, P. VITEK ${ }^{23}$, O. URBAN ${ }^{24}$, M. HANOUSEK ${ }^{4}$, P. KOMINEK ${ }^{12}$ \\ ${ }^{1}$ Department of Otolaryngology, University Hospital Ostrava, Ostrava, Czech Republic; ${ }^{2}$ Faculty of Medicine, \\ University of Ostrava, Ostrava, Czech Republic; ${ }^{3}$ Beskydy Gastrocentre, Hospital Frýdek-Místek, Frýdek-Místek, \\ Czech Republic; ${ }^{4}$ Gastroenterology Department, Vitkovicka Hospital, Ostrava, Czech Republic
}

\section{SUMMARY}

The objective of the present study was to determine if there is correlation between signs of reflux laryngitis (RL) and reflux oesophagitis (RE) in patients with gastro-oesophageal reflux disease (GORD) symptoms. Laryngeal photography obtained from patients during oesophagogastroduodenoscopy were examined by two otolaryngologists experienced in the field of extra-oesophageal reflux regarding the presence and severity of RL. The presence of RE was evaluated by gastroenterologist. Smokers, heavy drinkers and patients with bronchial asthma were excluded from the statistical analysis. A total of 681 patients were analysed. RL was diagnosed in 367 (53.9\%) cases, of whom 182 patients had mild, 118 moderate and 67 severe (Reflux Finding Score > 7) RL. RE was diagnosed in 103 (28.1\%) patients with RL and in $80(25.7 \%)$ patients without RL. Neither the difference between the overall group of patients with RL and those without (OR 1.141, 95\% CI 0.811-1.605, $\mathrm{p}=0.448$ ), nor the differences between the respective subgroups of patients with mild, moderate and severe RL and those without RL were statistically significant. The OR and 95\% CI for mild, moderate and severe RL were 1.042, 95\% CI 0.712-1.526, $\mathrm{p}=0.834,1.182,95 \%$ CI $0.764-1.831, \mathrm{p}=0.453$ and $1.0,95 \%$ CI $0.566-1.766, \mathrm{p}=0.999$ respectively. It can be concluded that there is no correlation between RL and RE in patients with GORD symptoms.

KEY WORDS: Extra-oesophageal reflux $\bullet$ Laryngopharyngeal reflux $・$ Reflux laryngitis $\bullet$ Reflux oesophagitis $\bullet$ Gastro-oesophageal reflux $\bullet$ Reflux Finding Score

\section{RIASSUNTO}

Lo scopo dello studio è stato determinare l'esistenza di una correlazione tra i segni di laringite da reflusso (RL) ed esofagite da reflusso (RE) in pazienti con sintomi da malattia da reflusso gastroesofageo (GORD). Durante l'esecuzione di esofagogastroduodenoscopie, sono state ottenute fotografie laringee, le quali sono state esaminate da otorinolaringoiatri esperti di reflusso extra-esofageo al fine di valutare la presenza e la gravità di RL. La presenza di RE, invece, è stata valutata dai gastroenterologi. Fumatori, alcolisti e pazienti con asma bronchiale sono stati esclusi dall'analisi statistica. Sono stati analizzati 681 pazienti. RL è stata diagnosticata in 367 (53,9\%) pazienti, dei quali 182 avevano una forma lieve, 118 una forma moderata, e 67 una forma severa (Reflux Finding Score > 7). RE è stata diagnosticata in $103(28,1 \%)$ pazienti con $R L$ e in $80(25,7 \%)$ pazienti senza $R L$. In merito alla presenza di RE, la differenza tra l'intero gruppo di pazienti con RL e quelli senza RL non è stata statisticamente significativa (OR 1.141, 95\% CI 0.811-1.605, $p=0.448)$, e allo stesso modo non si sono rivelate statisticamente significative le differenze tra ciascuno dei sottogruppi di pazienti con RL lieve, moderata e severa, e quelli senza RL. L'OR e il 95\% CI per RL lieve, moderata e severa sono stati rispettivamente i seguenti: 1.042, 95\% CI 0.712-1.526, $p=0.834$, $1.182,95 \%$ CI 0.764-1.831, $p=0.453$ and 1.0, 95\% CI 0.566-1.766, $p=0.999$. In conclusione, non è risultata nessuna correlazione tra $R L$ e RE in pazienti con sintomi da malattia da reflusso gastroesofageo.

PAROLE CHIAVE: Reflusso extra-esofageo $・$ Reflusso faringolaringeo $\bullet$ Laringite da reflusso $\bullet$ Esofagite da reflusso $\bullet$ Reflusso gastroesofageo $\bullet$ Reflux Finding Score

Acta Otorhinolaryngol Ital 2017;37:401-405

\section{Introduction}

It is broadly accepted that reflux oesophagitis (RE) is present in less than one-third of patients with laryngopharyngeal reflux (LPR), and oesophagogastroduodenoscopy (EGD) is not routinely recommended for these patients by otolar- yngologists ${ }^{1}$. On the other hand, some studies have shown that extra-oesophageal symptoms may be the first sign of severe RE, as well as of adenocarcinoma ${ }^{2}$. If a patient suffers from frequent typical symptoms of gastro-oesophageal reflux disease (GORD), such as heartburn and regurgitation, or experiences some of the "alarm symptoms" such 
as dysphagia, odynophagia, weight loss, anaemia etc., EGD should be done to understand the severity of the pathological changes within the oesophagus ${ }^{1}$. However, most patients with extra-oesophageal symptoms do not suffer from such symptoms ${ }^{13}$. As a result of the above mentioned contradiction, otolaryngologists often struggle with a dilemma: should a patient with extra-oesophageal symptoms and signs of reflux disease be referred for EGD or not?

The objective of the present study was to determine if there is correlation between signs of reflux laryngitis (RL) and reflux oesophagitis (RE) in patients with GORD symptoms. If this were true, the presence of reflux laryngitis (RL), which is considered the most characteristic endoscopic sign of LPR, would mean that reflux changes within the oesophagus (erosive oesophagitis) could be expected frequently in patients with GORD symptoms and patient should be referred for EGD. From this point of view, laryngoscopy done by an otolaryngologist as a routine examination would bring additional information in decision-making process whether patient with GORD symptoms should be referred to upper gastrointestinal endoscopy. To our knowledge, this is the largest study to examine the association between RL and RE in patients with GORD symptoms, and the first study to use Reflux Finding Score (RFS) to quantify laryngeal changes for this reason.

\section{Materials and methods}

The prospective study was performed in accordance with the 1983 Declaration of Helsinki, the requirements of good clinical practice and all applicable regulatory requirements, and was approved by the Institutional Review Board. Written informed consent was obtained from all participants before initiating any procedure.
Patients undergoing EGD due to GORD symptoms (heartburn, regurgitation) and/or upper gastrointestinal discomfort/dyspepsia lasting for at least two months within the study period of January 2014 to December 2014 were included. Epidemiologic data (age, sex, BMI, bronchial asthma, smoking history, alcohol abuse) were obtained via questionnaire. The presence of RE was established and classified by a gastroenterologist according to the Los Angeles classification (grades A-D). The high-definition endoscope Olympus GIF H180 was used for all examinations. As part of the EGD, laryngeal photography of high-definition quality was obtained from all patients (Fig. 1).

The presence of RL was determined from photographs by two otolaryngologists (KZ, PK) experienced in the field of LPR and blinded for the result of EGD. RFS proposed by Belafsky et al. was not used for the initial evaluation of laryngeal changes because it is not widely used as first-line by otolaryngologists. To make the results of our study widely usable, a much easier system of evaluation of the laryngeal changes was used. Three degrees (mild, moderate, severe) of RL were distinguished. Patients with changes limited to the posterior commissure or arytenoids (hypertrophy, oedema, erythema) were included in group I (mild changes). Patients with changes in both the posterior commissure and arytenoids (hypertrophy, oedema, erythema) were included in group II (moderate changes). Patients with more severe changes affecting at least three areas of the larynx (e.g. erythema of the arytenoids, oedema of the vocal cords, pseudosulcus vocalis, hypertrophy of the false vocal cords, ventricular obliteration, granuloma etc.) were included in group III (severe changes) (Fig. 1). After this initial selection, group III was re-evaluated using RFS. All patients in group III had RFS higher than seven, which is the diagnostic threshold for LPR for this tool.

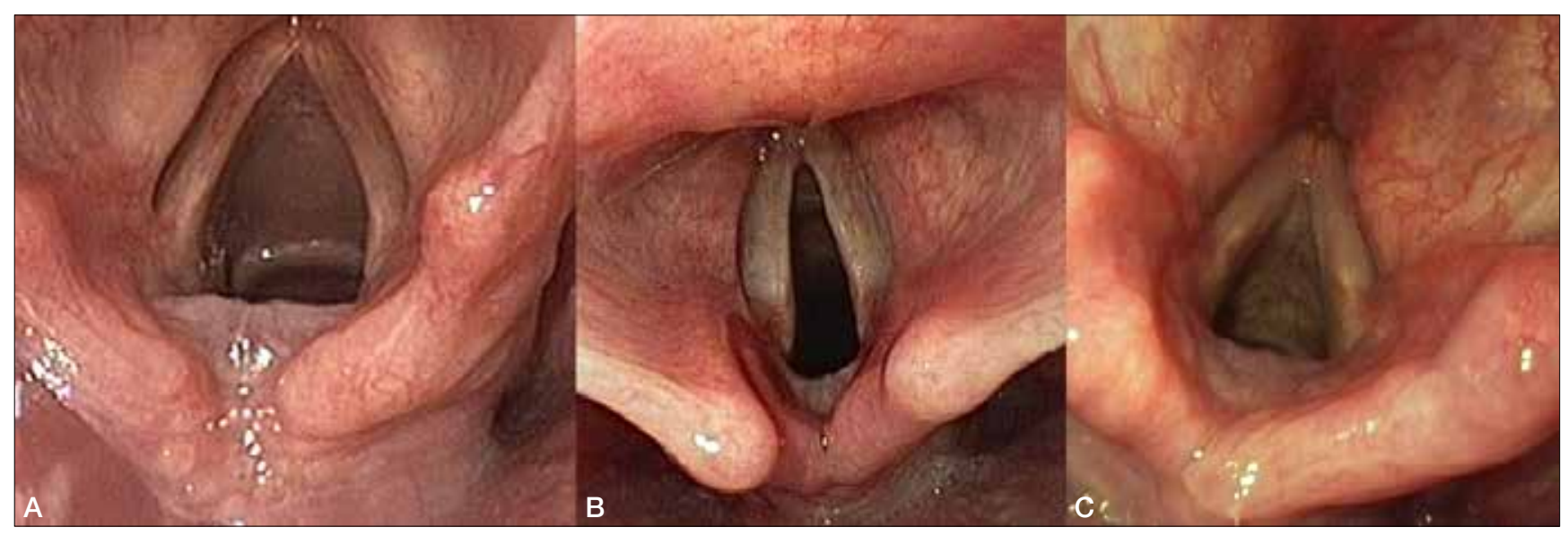

Fig. 1. High definition pictures obtained during routine oesophagogastroduodenoscopy. Three grades of reflux laryngitis were determined in all patients: a - mild (hypertrophy, oedema or erythema limited only on the posterior commissure or arytenoids)

b - moderate (hypertrophy, oedema or erythema present on both the posterior commissure and arytenoids)

c - severe (pathological changes affecting at least three areas of the larynx (e.g. erythema of the arytenoids, oedema of the vocal cords, pseudosulcus vocalis, hypertrophy of the false vocal cords, ventricular obliteration, granuloma etc.). 
Smokers, heavy drinkers and patients with bronchial asthma were excluded from the statistical analysis, because inflammatory changes of the larynx are very common within these groups of patients and the results of the study could be biased.

The presence of RE in the groups of patients with RL and without RL as well as in all three subgroups (mild, moderate, severe) of RL was statistically analysed. Univariate logistic regression analysis was used to assess the relationship between RL and RE - by odds ratios (OR) and their 95\% confidence interval (CI 95\%). The dependent variable was the presence of RE. Statistical analysis was performed using SPSS statistical package (version 19.0).

\section{Results}

A total of 1224 patients were recruited for the study, 35 of whom were excluded because of the low quality of their laryngeal photographs. An additional 508 patients (smokers, heavy drinkers, patients with bronchial asthma) were excluded, and thus 681 patients (303 male, 378 female, mean age $57, \mathrm{SD} \pm 16$ ) were analysed.

RL was diagnosed in 367 (53.9\%) patients, of whom 182 patients had mild, 118 moderate and 67 severe (RFS $>7$ ) RL. RE was diagnosed in 103 (28.1\%) out of 367 patients with RL and in $80(25.7 \%)$ out of 314 patients without $\mathrm{RL}$. We ascertained that RE was not statistically more frequent in the overall group of patients with RL (OR 1.141, $95 \%$ CI $0.811-1.605, p=0.448)$, nor in the subgroups of patients with mild, moderate and severe (RFS $>7$ ) RL than in patients without RL. The OR and 95\% CI for mild, moderate and severe reflux laryngitis were 1.042, $95 \%$ CI $0.712-1.526, \mathrm{p}=0.834,1.182,95 \%$ CI 0.764 $1.831, \mathrm{p}=0.453$ and $1.0,95 \% \mathrm{CI} 0.566-1.766, \mathrm{p}=0.999$ respectively.

\section{Discussion}

LPR and its relationship to GORD and RE continues to be a controversial issue because there is a lack of diagnostic criteria and inconsistency in response to therapy. Nevertheless, it is a very real problem and affects hundreds of thousands of patients annually ${ }^{45}$. It is estimated that up to $10-15 \%$ of all visits to otolaryngology offices are prompted by manifestations of LPR ${ }^{16-8}$. One of the daily dilemmas otolaryngologists struggle with concerns whether or not a patient with GORD symptoms who do not fall within the "alarm symptoms" group and with concurrent signs suggesting LPR should be referred for EGD to determine the extent of pathological changes in the oesophagus.

While our understanding of LPR continues to evolve, one fact is already clear. LPR is considered to be a distinct disorder from GORD, with a different pathophysiology ${ }^{34}$. When compared to the oesophageal mucosa, the laryngeal mucosa is more susceptible to injury, which may be caused by much lower levels of acid and pepsin exposure than those capable of damaging the oesophageal epithelium ${ }^{4}$. Moreover, the negative role of biliary laryngopharyngeal reflux in the pathogenesis of chronic laryngeal changes has been revealed recently ${ }^{9}$. This condition, as an acid one, seems to represent an important dangerous, endogenous risk factor involved in the pathogenesis of inflammatory, precancerous and neoplastic laryngeal lesions ${ }^{9}$. As a result, many patients diagnosed with LPR do not suffer from the classic symptoms of GORD (heartburn, regurgitation) and oerosive esophagitis. Therefore, EGD is not routinely recommended for patients with isolated LPR by otolaryngologists ${ }^{110}$. For example, an international survey conducted by Book et al. demonstrated that only 5 (4.4\%) of 120 otolaryngologists reported ordering EGD as a firstline adjunctive test for patients with suspected LPR ${ }^{10}$.

On the other hand, some case control studies have shown an association between RE and RL ${ }^{5811-14}$. Also, it has been estimated that up to $50 \%$ of patients with laryngeal and voice disorders have reflux ${ }^{1}$, prompting some authors to recommend endoscopic evaluation of the upper gastrointestinal tract in all patients with $\mathrm{LPR}^{4{ }^{15}}$. The reasoning is that some symptoms of more severe conditions within the oesophagus may be masked by empiric therapy. A peculiar subgroup of patients requiring EGD are those with chronic cough. Reawis et al. demonstrated that these individuals are more likely to have metaplastic changes of the oesophagus than those with classic symptoms of GORD ${ }^{2}$. In our study, we set out to understand whether RL, which is the most common and easy to access independent sign of LPR, is of diagnostic importance for prediction of RE in patients with GORD symptoms. We decided not to evaluate potential symptoms of LPR (voice problems, throat cleaning, globus pharyngeus, cough, etc.) and not to fill out questionnaire reflux symptom index in our study. The main reason is that symptoms of LPR and Reflux symptom index are even less specific than laryngeal signs of LPR, very prone to transitory changes and patient dependent with very high risk of subjective bias.

On the other hand, RL is considered to be one of the most characteristic signs of LPR. An international survey of 120 otolaryngologists conducted by Book et al. showed that arytenoid oedema and erythema and posterior commissure hypertrophy were considered the most typical signs of LPR by most ${ }^{10}$. Similarly, a survey of more than 700 otolaryngologists revealed that the two signs most likely to be used to diagnose laryngitis associated with reflux were erythema and oedema of the larynx ${ }^{16}$.

Nevertheless, it is very important to keep in mind that the signs of LPR are not very specific and can be the result of injury by non-GORD mechanisms (tobacco, alcohol, allergies, infection, postnasal discharge, vocal trauma etc.). This often leads to over-diagnosis of this condition and makes the study of the relationship between LPR and GORD (with or without RE) complicated and challeng- 
ing. For example, Hicks et al. revealed at least one finding considered to be associated with reflux in $86 \%$ of 105 healthy volunteers without any throat symptoms ${ }^{17}$. Additionally, abnormal laryngeal signs are more likely to be suspected when flexible rather than rigid laryngoscopes are used, suggesting that flexible laryngoscopy is more sensitive but less specific in identifying laryngeal tissue irritation ${ }^{18}$. Besides the non-specificity of the signs currently employed in diagnosing LPR, an additional problem is the inter- and intra-observer variability of laryngoscopic exams. To improve reliability of the laryngoscopic evaluation, RFS was proposed by Belafsky et al. ${ }^{19}$. Initial studies found good inter- and intra-observer reproducibility of this tool. However, RFS is seldom used in clinical practice as it is not user friendly, as well as being difficult to remember and time consuming. The reliability of this score has been questioned as well ${ }^{20}$.

In the present study, three degrees (mild, moderate, severe) of RL were identified (Fig. 1) and patients divided into three groups accordingly. The groups "mild" and "moderate" included patients with laryngeal changes limited to the posterior commissure and/or arytenoids, for these changes are often construed by otolaryngologists as characteristic signs of reflux. The group "severe" included patients with many laryngeal signs of LPR, and all of these patients had RFS higher than seven. We did not find that RE was statistically more frequent in the overall group of patients with RL in comparison to the group of patients without RL. Moreover, $\mathrm{RE}$ was not statistically more frequent in subgroups of patients with mild, moderate and severe (RFS higher than seven) RL than in the group without RL. Thus our result is consistent with the result of a study evaluating the prevalence of laryngeal signs in GORD versus non-GORD patients (based on EGD) conducted by Vavricka et al. ${ }^{20}$. The authors found that there was no difference between the groups, suggesting the lack of diagnostic specificity of laryngeal signs for GORD $^{21}$. Also, another smaller study conducted by Tauber et al. did not find statistically significant differences in the above mentioned laryngeal changes between GORD and non-GORD groups ${ }^{8}$.

Moreover, Cammarota et al. referred that 52 of 83 patients with laryngitis $(63 \%)$ had no erosion of the oesophageal mucosa. The authors concluded that inflammation of the laryngeal epithelium (when defense mechanisms are absent) is more frequent than erosive oesophagitis in patients with chronic reflux symptoms ${ }^{2223}$. They recommend future studies in this area to better delineate these associations.

Going beyond the results of formerly mentioned studies, we selected a group of patients with severe laryngeal changes, which corresponded to RFS over seven. Even in this group of patients, RE was not found to be statistically more frequent. To our knowledge, this result is novel and has not been published in the literature to date.

As a result of our study, it can be concluded that laryngeal signs (reflux laryngitis) in patients with GORD symptoms are not of diagnostic specificity for RE. This supports the claim that LPR and GORD are two distinct diseases and that otolaryngologists cannot predict the presence of RE from the laryngeal examination. The other possible interpretation of our result is that signs of LPR are so non-specific and widely present in the population that the relationship with RE cannot be reliably established. Of course, in some cases these two entities can coexist and this can be the reason for the broad range of association reported in the literature. RE confirmed by EGD was reported in 26\% (Paterson 1997), 43\% (Deveney 1993 and Tauber 2002) and 62\% (Koufman 1991) of patients with LPR ${ }^{681213}$. Likewise, RE was confirmed in $28 \%$ of patients with RL in the present study.

\section{Conclusions}

There is no correlation between reflux laryngitis and reflux oesophagitis in patients with GORD symptoms.

\section{Acknowledgements}

The authors would like to thank MSc. Hana Tomášková, $\mathrm{Ph}$. D. from the Institute of Epidemiology and Public Health, Medical Faculty of the Ostrava University, Czech Republic, for help with statistical analysis.

\section{References}

1 Sataloff RT et al. Reflux laryngitis and related disorders. First Edition. San Diego: Plural Publishing; 2006

2 Reavis KM, Morris CD, Gopal DV, et al. Laryngopharyngeal reflux symptoms better predict the presence of esophageal adenocarcinoma than typical gastroesophageal reflux symptoms. Ann Surg 2004;239:849-56.

3 Koufman JA. Laryngopharyngeal reflux is different from classic gastroesophageal reflux disease. Ear Nose Throat $\mathbf{J}$ 2002;81:7-9.

4 Weinberger PM, Postma GN. Laryngopharyngeal reflux from the otolaryngologist's perspective. In: Vaezi MF, editor. Extraesophageal reflux. San Diego: Plural Publishing; 2009. p. 49-66.

5 Galli J, Scarano E, Agostino S, et al. Pharyngolaryngeal reflux in outpatient clinical practice: personal experience. Acta Otorhinolaryngol Ital 2003;23:38-42.

6 Koufman JA. The otolaryngologic manifestations of gastroesophageal reflux disease: a clinical investigation of 225 patients using ambulatory 24- $h$ ph monitoring and an experimental investigation of the role of acid and pepsin in the development of laryngeal injury. Laryngoscope 1991;101:1-78.

7 Richter JE. Extraesophageal presentations of gastroesophageal reflux disease: an overwiew. Am J Gastroenterol 2000;95:S1-S3.

8 Tauber S, Gross M, Issing WJ. Association of laryngopharyngeal symptoms with gastroesophageal reflux disease. Laryngoscope 2002;112:879-86.

9 Galli J, Cammarota G, De Corso E, et al. Biliary laryngopharyngeal reflux: a new pathological entity. Current Op Otolaryngol Head Neck Surg 2006;14:128-32. 
10 Book DT, Rhee JS, Toohill RJ, et al. Perspectives in laryngopharyngeal reflux: an international survey. Laryngoscope 2002;112:1399-1406.

11 El-Serag HB, Sonnenberg A. Comorbid occurrence of laryngeal or pulmonary disease with esophagitis in United States military veterans. Gastroenterology 1997;113:755-60.

12 Paterson WG. Extraesophageal complications of gastroesophageal reflux disease. Can J Gastroenterol 1997;11:45B-50B.

13 Deveney CW, Benner K, Cohen J. Gastroesophageal reflux and laryngeal disease. Arch Surg 1993;128:1021-7.

14 Koufman JA, Amin MR, Panetti M. Prevalence of reflux in 113 consecutive patients with laryngeal and voice disorders. Otolaryngol Head Neck Surg 2000;123:385-8.

15 Bove MJ, Rosen C. Diagnosis and management of laryngopharyngeal reflux disease. Curr Opin Otolaryngol Head Neck Surg 2006;14:116-23.

16 Ahmed TF, Khandwala F, Abelson TI, et al. Chronic laryngitis associated with gastroesophageal reflux: prospective assessment of differences in practice patterns between gastroenterologists and ENT physicians. Am J Gastroenterol 2006;101:470-8.

17 Hicks DM, Ours TM, Abelson TI, et al. The prevalence of hypopharynx findings associated with gastroesophageal reflux in normal volunteers. J Voice 2002;16:564-7.
18 Milstein CF, Charbel S, Hicks DM, et al. Prevalence of laryngeal irritation signs associated with reflux in asymptomatic volunteers: impact of endoscopic technique (rigid vs. flexible laryngoscope). Laryngoscope 2005;115:2256-61.

19 Belafsky CP, Postma GN, Koufman JM. The validity and reliability of the Reflux Finding Score. Laryngoscope 2001;111:1313-7.

20 Branski RC, Bhattacharyya N, Shaprio J. The reliability of the assessment of endoscopic laryngeal findings associated with laryngopharyngeal reflux disease. Laryngoscope 2002;112:1019-24.

21 Vavricka SR, Storck CA, Wildi SM, et al. Limited diagnostic value of laryngopharyngeal lesions in patients with gastroesophageal reflux during routine upper gastrointestinal endoscopy. Am J Gastroenterol 2007;102:716-22.

22 Cammarota G, Galli J, Agostino S, et al. Accuracy of laryngeal examination during upper gastrointestinal endoscopy for premalignancy screening: prospective study in patients with or without reflux symptoms. Endoscopy 2006;38:376-381.

23 Cammarota G, Agostino S, Rigante M, et al. Preliminary laryngeal examination during magnifying upper gastrointestinal videoendoscopy in two patients with reflux symptoms. Endoscopy 2006;38:287. 